\title{
Comunidades tradicionais e Unidades de Conservação: etnoconhecimento no entorno do Parque Estadual das Lauráceas, Paraná
}

\author{
Comunidades tradicionales y unidades de conservación: \\ etnoconocimiento en el entorno del Parque Estadual de las \\ Lauráceas, Paraná
}

\section{Traditional communities and protected areas: ethnoknowledge in the Lauraceas State Park Surroundings, Paraná State}

\author{
Jandaira S. Moscal \\ jandamoscal@gmail.com
}

Doutoranda no PPG em Meio Ambiente e Desenvolvimento da UFPR

Tatiana C. G. Kaminski

tati.kaminski@gmail.com

Mestranda no PPG em Meio Ambiente e Desenvolvimento da UFPR

Resumo: O Parque Estadual das Lauráceas é o ponto de partida para uma amostra do diverso conhecimento popular contido no entorno desta porção de Mata Atlântica, onde o saber fazer das comunidades tradicionais abrange diversas práticas de uso da natureza que foram desenvolvidas para garantir sua sobrevivência e manter suas tradições. Reconhecer e valorizar o etnoconhecimento das comunidades quilombolas vizinhas ao Parque Estadual das Lauráceas torna-se uma estratégia inteligente para a gestão participativa dos recursos naturais, além de fortalecer a conservação dos remanescentes naturais e culturais do território do Vale do Ribeira Paranaense.

Palavras-chave: Quilombolas. Conhecimento tradicional. Etnoconservação.

Resumen: El Parque Estadual de las Lauráceas es el punto de partida para una muestra de la diversidad del conocimiento popular contenido en el entorno de esta porción de la Mata Atlántica, donde el saber de las comunidades tradicionales abarca diversas prácticas del uso de la naturaleza que fueran desarrolladas para garantizar su supervivencia y preservar sus tradiciones. Reconocer y valorizar el etnoconocimiento de las comunidades quilombolas vecinas al Parque Estadual de las Lauráceas tornase una estrategia inteligente para la gestión participativa de los recursos naturales, además de fortalecer con la conservación de los remanentes naturales y culturales del territorio del Vale do Ribeira Paranaense.

Palabras-Clave: Quilombolas, Conocimientos tradicionales. Etnoconservation.

Abstract: The Lauraceas State Park represents the starting point for a varied popular knowledge sample of the Atlantic forest, where the traditional knowledge of the communities includes several practices of the use of nature that have been developed 
to ensure their survival and maintain their traditions. Recognizing and valuing the ethnoknowledge from quilombolas communities in the park surroundings become an effective strategy for participatory management of natural resources in addition to strengthening the conservation of natural and cultural remnants of the Ribeira Valley in Paraná State.

Keywords: Quilombolas. Traditional knowledge. Ethnoconservation.

\section{INTRODUÇÃO}

Com relevo fortemente ondulado, de muitas montanhas e rios sinuosos, o Vale do Ribeira abriga diferentes territórios, formando um cenário de relevante diversidade étnica, cultural, ecológica e política dentro da maior área contínua de Mata Atlântica do país. A região é território institucional porque está integrado ao Programa Territórios da Cidadania, geopolítico porque configura a bacia hidrográfica do rio Ribeira de Iguape, e etnocultural porque é habitada historicamente por populações indígenas e quilombolas. Na porção paulista, o Vale do Ribeira é composto por 22 municípios, enquanto no Paraná 7 integram o território. Entretanto, ao considerar a bacia hidrográfica, Silva (2013) afirma que 21 outros municípios do Paraná e 18 de São Paulo ocupam a unidade territorial parcialmente.

É neste complexo cenário que se encontra o Parque Estadual das Lauráceas (PEL), unidade de conservação (UC) criada em 1979 com o objetivo de conservar um importante remanescente florestal da outrora vasta biodiversidade paranaense, além de promover a visitação pública, a pesquisa e a educação ambiental. Com área de 27.524ha, o PEL abrange três municípios: Adrianópolis, Bocaiúva do Sul e Tunas do Paraná.

A lei no 9.985/2000 define como zona de amortecimento (ZM) "o entorno de uma UC onde as atividades humanas estão sujeitas a normas e restrições específicas, com o propósito de minimizar os impactos negativos sobre a unidade" (art.2 $2^{\circ}$ - XVIII). Neste contexto, estão localizadas na zona de amortecimento do PEL seis comunidades remanescentes de quilombo certificadas pela Fundação Cultural Palmares, as quais são: Areia Branca, Estreitinho, Três Canais, Córrego do Franco, João Surá e São João. Estas três últimas estão em processo de titulação de terras, fato que configura o último passo para que seja reconhecido pelo Estado o direito à permanência e à reprodução sociocultural das populações quilombolas, conforme prevê o artigo 68 do Ato das Disposições Constitucionais Transitórias da Constituição de 1988, regulamentado pelo decreto nº 4.887/2003.

Tais comunidades construíram historicamente um saber-fazer próprio de sua visão de mundo, transmitido pelas gerações e marcado pela oralidade presente nas práticas linguageiras. Nelas estão incluídos saberes inatos sobre o manejo dos recursos naturais de seus territórios, que embora tenham sido ameaçados pelo estreitamento da extensão territorial disponível desde a implantação do PEL e crescente ação de vastos plantios de pinus e pastagens, continuam a propagar a cultura praticada por seus antepassados. 
Para ilustrar a abordagem acerca do etnoconhecimento exposto neste trabalho, foi traçado um recorte do projeto "Quilombolas das Lauráceas: Difusão do Patrimônio Cultural do Vale do Ribeiro Paranaense", realizado através de uma bolsa de pesquisa da Fundação Nacional de Artes (FUNARTE) no ano de 2011. A pesquisa teve como objetivos principais retratar os protagonistas que participam na manutenção do patrimônio cultural dos quilombolas do Vale do Ribeira, ao mesmo tempo em que se pretendeu contribuir com a discussão da etnoconservação como ferramenta adequada para conservar ecossistemas naturais, com enfoque para áreas protegidas. Para tanto foram realizadas parcerias com quatro comunidades quilombolas localizadas no entorno do PEL: Areia Branca, Córrego do Franco, Estreitinho e São João, das quais, através do estabelecimento de atividades de campo, foram colhidas entrevistas, filmagens, fotografias e informações em conversas informais. Também foi realizada entrevista com gestores públicos que trabalharam na região, com o intuito de corroborar o conteúdo da linha desta pesquisa.

\section{DESENVOLVIMENTO TEÓRICO-METODOLÓGICO}

\section{Para Costa apud Löwen Sahr et al.:}

A etnociência é um campo relativamente recente da ciência, tendo sua origem na Antropologia. Ela abarca um conteúdo interdisciplinar no estudo das mais diversas formas do conhecimento humano sobre o meio ambiente em que determinado grupo se insere. Seu prefixo etno refere-se ao sistema de conhecimento e cognição típicos de uma cultura marcada por aspectos geracionais, gestuais e linguísticos. (LÖWEN SAHR et al., 2011, p. 134).

De acordo com Bonnemaison:

A noção de territorialidade emana de aspectos presentes em uma etnia, no sentido de que ela é, antes de tudo, a relação culturalmente vivida entre um grupo humano e uma trama de lugares hierarquizados e interdependentes, cujo traçado no solo constitui um sistema espacial - dito de outra forma, um território. (BONNEMAISON, 2006, p.97).

A abordagem teórica do estudo das unidades de conservação tem no conceito de território um grande espectro de possibilidades de discussão, tanto em relação à visão sobre natureza quanto às questões que dizem respeito à sociedade em geral, e agrupamentos sociais em particular. Além disso, os recentes debates sobre a problemática das unidades de conservação têm demandado uma aproximação entre as múltiplas abordagens do território. (VALLEJO, 2002).

Apesar de ser um conceito central para a Geografia, a noção de território e territorialidade, por dizer respeito à espacialidade humana, mantém certa tradição também em outras áreas, cada uma com um enfoque centrado em uma determinada perspectiva. (HAESBAERT, 2011). Nas Ciências Naturais apresenta ênfase no estudo da ecologia das espécies e das populações naturais; nas Ciências Políticas, o território está estreitamente 
relacionado com a formação do Estado; na antropologia, o conceito é relacionado às sociedades tradicionais, nas quais os vínculos espaciais são bastante pronunciados.

O uso do território pelo homem é uma realidade que deve ser considerada quando se planeja uma unidade de conservação. Atualmente existe um reconhecimento crescente de que a lacuna deixada pela ausência de envolvimento da população local é o elemento principal que fragiliza as estratégias de manejo de conservação da natureza. (PRIMACK; RODRIGUES, 2001). Com isso, os exemplos clássicos de conservação da natureza, sem qualquer interferência humana, vêm sendo revistos e readaptados considerando especificidades regionais e locais.

Em grande parte do mundo o principal instrumento para a conservação da biodiversidade é a criação de áreas protegidas, localizadas e demarcadas como pedaço de relevante interesse ecológico, e mantidas sobre regimes especiais de regulação. $\mathrm{O}$ modelo de unidade de conservação adotado no Brasil deriva da concepção de natureza selvagem criada pelos Estados Unidos, entendida como lugares de contemplação e que devem ser separados da intervenção humana. Dentro de um quadro de evolução temporal da noção de conservação da natureza, tem-se que a partir da década de 1960 os países do Sul adotaram a estratégia conservacionista praticada pelos países do Norte, traduzida a partir da criação de um grande número de parques. Na prática, entretanto, a visão conservacionista do homem moderno como ser degradante em primeira instância começou a dar sinais de fracasso porque não se pensou suas especificidades regionais nem as características históricas de seu processo de colonização e ocupação territorial.

Ao considerar o cenário conservacionista em escala global, a discussão sobre o conceito de comunidade tradicional aparece com a expressão indigenous people (ICIHI, 1987), definida a partir de uma referência aos habitantes de terras colonizadas que são etnicamente diferentes das sociedades dominantes dos países onde vivem. (VIANNA, 2008). Na década de 1970, o movimento conservacionista se uniu a grupos de direitos humanos para corroborar a defesa aos indigenous people, em oposição aos modelos hegemônicos da sociedade urbano-industrial. Entretanto, a ação deixou de ser convergente quando confrontados os objetivos finais de defesa de cada movimento. Aos conservacionistas caberia uma posição que, em primeira instância, defende a instalação de áreas protegidas como resposta à ação predatória do homem moderno, atribuindo também às populações locais as causas da degradação ambiental sem fazer distinção entre o modo de organização de diferentes sociedades, seus níveis de inserção com a economia global e seus padrões de consumo e manejo de recursos naturais.

No Brasil, a noção de indigenous people foi defendida pelo movimento ambientalista da década de 1970, que inaugurou a defesa sobre considerá-las sustentáveis. Naquele momento, era atribuído aos índios uma função ecológica dentro da dinâmica da natureza, uma vez que a prática de abrir pequenas clareiras em meio à mata permitiria a promoção da diversidade de espécies pioneiras e de animais, e renovaria o tecido cicatrizante dos ecossistemas. (DIEGUES, 1994). Aliada a esta característica ecológica, a herança cultural indígena esteve presente em todos os ciclos econômicos da história do Brasil, e forjou uma sociedade rústica, dotada de subculturas regionais (CANDIDO, 1964), ou o que Arruda 
(1999) chama de "cultura rústica", resultado da produção de novos arranjos socioculturais e regionais - obtidos a partir da agricultura, da base alimentar e da produção do trabalho indígena - encontrado também nas culturas crioula, caipira, caiçara, sertaneja, gaúcha, e cabocla. (RIBEIRO, 1995).

Na prática, por outro lado, apesar de considerar o fato de que essas populações corporificam um modo de vida mais harmonioso com o ambiente no sentido da relação com os recursos naturais, elas mesmas vem sendo sistematicamente desprezadas e afastadas de qualquer contribuição que possam oferecer à elaboração das políticas públicas regionais. Exemplo disso é a ausência de ações especificas em planos de manejo de unidades de conservação de proteção integral.

A alternativa que vem sendo discutida para o modelo de conservação na natureza em vigor é a etnoconservação, perspectiva que defende a construção de uma nova aliança entre o homem e a natureza, baseada, entre outros pontos, na importância das comunidades tradicionais indígenas e não indígenas na conservação das matas e outros ecossistemas presentes nos territórios que habitam. A valorização do conhecimento e das práticas de manejo dessas populações deveria constituir uma das pilastras de um novo conservacionismo nos países do Sul. (DIEGUES, 2000).

Segundo Toledo e Barrera-Bassols:

O surgimento e desenvolvimento da etnoecologia, com seu enfoque holístico e multidisciplinar, permitiram o estudo do complexo integrado pelo sistema de crenças (kosmos), o conjunto de conhecimentos (corpus) e de práticas produtivas (praxis), o que torna possível compreender cabalmente as relações que se estabelecem entre a interpretação e leitura e o uso ou manejo da natureza e seus processos. O enfoque etnoecológico busca então integrar, comparar e validar ambos os modelos para criar diretrizes que apontem a implementação de propostas de desenvolvimento local endógeno ou sustentável com a plena participação dos atores locais. Assim, seu enfoque busca encontrar possíveis sinergias entre ambas as maneiras de valorizar o mundo e o consequente aproveitamento dos recursos naturais. (TOLEDO; BARRERABASSOLS, 2006, p. 41).

A partir da década de 1990, a utilização do termo comunidades tradicionais é convencionado tanto pela academia quanto pelo governo federal. Já na década de 2000, o Decreto n6040/2007 surge com a perspectiva de instaurar a Política Nacional de Desenvolvimento Sustentável dos Povos e Comunidades Tradicionais, tendo a Comissão Nacional de Desenvolvimento Sustentável dos Povos e Comunidades Tradicionais (criada em 2006) a missão de coordenar a implementação do Decreto. Nele, é divulgado um conceito que ajuda a entender a expressão povos e comunidades tradicionais como sendo:

[Art. $3^{\circ}$ ] grupos culturalmente diferenciados e que se reconhecem como tais, que possuem formas próprias de organização social, que ocupam e usam territórios e recursos naturais como condição para sua reprodução cultural, social, religiosa, ancestral e econômica, utilizando conhecimentos, inovações e práticas gerados e transmitidos pela tradição. (BRASIL, 2006). 
Nesta definição estão os índios, quilombolas, faxinalenses, cipozeiros, ciganos, ribeirinhos, caiçaras, quebradeiras-de-coco-babaçu, geraizeiros, caatingueiros, pantaneiros, seringueiros e outras comunidades tradicionais. Segundo Waldman (2006), em todas as sociedades tradicionais, a presença da natureza nos mitos, nas cosmogonias, nas representações simbólicas, nas manifestações religiosas e, além disso, nas práticas materiais e nas transformações incorporadas à paisagem criada sempre foi marcante.

Nesse contexto, a questão da relação natureza e sociedade trata muito mais de administrar visões e interesse humanos, muitas vezes opostos, do que manejar processos naturais. É evidente que as populações tradicionais não são os únicos atores envolvidos na tarefa da conservação, e outras responsabilidades como as dos grupos urbanos, agricultores comerciais, etc. também devem ser levados em consideração. O que se pode dizer é que as comunidades tradicionais podem ser aliadas nesse exercício, o que também implica em afastar a visão romântica e utópica por vezes destinada a elas como conservadoras natas. Não bastasse isso, muitas dessas comunidades tem sofrido, nas últimas décadas, processos de deterioração social e cultural decorrentes de crescente inserção nas sociedades urbano-industriais, além de perda também crescente de suas tecnologias patrimoniais e redução sistemática do acesso aos recursos naturais. (DIEGUES, 2000).

O processo de adaptação das culturas humanas do século XX aos seus respectivos ambientes não significa que a convivência e a sobrevivência sejam melhores ou mais vantajosas para os indivíduos. Pelo contrário, adaptar-se significou, em muitos casos, sobreviver por meio de numerosas concessões, por vezes com altos custos físicos e morais. Viertler (1988, p.20) coloca que adaptar-se significa apenas "lograr, sobreviver", e "não extinguir-se" como cultura humana ou grupo étnico. Se esta adaptação representa um progresso, este é sempre relativo, podendo, muitas vezes, manifestar-se por perdas culturais ou involuções. (Ibidem)

Segundo Toledo e Barrera-Bassols:

Todo produtor rural necessita dispor de "meios intelectuais", ou seja, de conhecimentos sobre seu entorno para realizar a apropriação de suas naturezas. Esses conhecimentos têm um valor substancial para clarificar as formas como as populações tradicionais percebem, concebem e conceituam os recursos, paisagens ou ecossistemas sobre os quais centram seus processos de reprodução sociocultural. Mais ainda, no contexto de uma economia de subsistência, esse conhecimento sobre a natureza se converte em um componente decisivo para o esboço e implantação de estratégias de sobrevivência. (TOLEDO; BARRERA-BASSOLS, 2009, p.35).

A criação do SNUC foi um reflexo da evolução histórica da política conservacionista, pois num momento anterior a ele, no Brasil, o discurso também era o de proteção integral sem interferência humana calcado nos argumentos da pesquisa, da beleza cênica e da saúde espiritual. A criação da categoria Reserva de Desenvolvimento Sustentável (RDS) corrobora a mudança de pensamento em relação às comunidades tradicionais e a conservação dos recursos naturais. A RDS representa uma área natural que abriga populações tradicionais, cuja existência baseia-se em sistemas sustentáveis de uso de recursos 
naturais, desenvolvidos ao longo de gerações e adaptados às condições ecológicas locais e que desempenham um papel fundamental na proteção da natureza e na manutenção da diversidade biológica. (BRASIL, 2000).

Porém, a interface entre gestão comunitária e gestão institucional dos recursos naturais é um tema recorrente que não encontra consenso. O poder público, muitas vezes, pratica uma postura utilitária com essas populações, pois as condições de como essas devem ou não pescar, caçar, fazer extrativismo e agricultura tende a serem impostas através de dispositivos legais e de fiscalização. Quando uma nova unidade de conservação é criada, ou quando as fronteiras de uma unidade já existente passam a ser rigidamente controladas, os moradores locais podem ter seu acesso negado a um recurso que eles sempre usaram ou até mesmo protegeram. (PRIMACK; RODRIGUES, 2001).

Um elemento essencial das estratégias de conservação deve ser a proteção da diversidade biológica dentro e fora das áreas protegidas. Para Diegues (2000) a diversidade biológica:

[...] é também uma construção cultural e social, na qual as espécies são objeto de conhecimento, de domesticação e uso, fonte de inspiração para mitos e rituais das sociedades tradicionais, e finalmente, mercadoria nas sociedades modernas. (DIEGUES, 2000, p. 1).

O perigo de se depender apenas de Parques e Reservas é que essa estratégia pode criar um 'estado de sítio', onde as espécies e comunidades dentro dos parques são rigorosamente protegidas enquanto que aquelas que estão fora podem ser livremente exploradas. Se as áreas que cercam os parques forem degradadas, de qualquer forma, a diversidade biológica dentro dos parques diminuirá também, sendo séria a perda de espécies nos parques pequenos. (PRIMACK; RODRIGUES, 2001).

Valorizar a inserção das UC no processo de desenvolvimento econômico local dentro de uma perspectiva sustentável se faz urgente na atualidade brasileira. Portanto, as políticas públicas em relação às áreas protegidas precisam integrar-se às demais políticas tradicionalmente setoriais. (PÁDUA, 2002). Torna-se necessário pensar em ações conjuntas de gestão dos recursos naturais, com valorização dos conhecimentos tradicionais aliado ao conhecimento científico para a formulação de políticas públicas que contemplem os interesses sociais, ecológicos e culturais de uma determinada localidade.

\section{RESULTADOS E DISCUSSÃO}

De acordo com Toledo e Barrera-Bassols (2009, p.40), "para que seja possível compreender as dinâmicas dos saberes tradicionais, é necessário entender a natureza da sabedoria local, que se baseia em uma complexa inter-relação entre crenças, conhecimentos e práticas". A apresentação de elementos do discurso de quilombolas que residem no interior do PEL surge, nesse sentido, com a intenção de demonstrar os valores contidos na relação que orienta o uso dos recursos. $\mathrm{O}$ acúmulo de conhecimentos construídos através 
da observação da natureza foi determinante na definição de estratégias de manejo dos recursos comuns, ainda que hoje estejam aparentemente menos presentes no tocante à intensidade de sua utilização.

Nos diálogos que buscavam entender como se dão essas relações, vários são os relatos sobre as maneiras de fazer as coisas antigamente. Muito se fala na união das pessoas, na lua minguante e em um jeito certo de usar os recursos naturais. Atualmente, apesar dos puxirões e reunidas serem raros, o conhecimento e a interdependência da natureza estão igualmente presentes. Durante os processos de transmissão dos conhecimentos pelas gerações, o que era repassado envolvia não só a confecção de um artefato, mas também os cuidados com o manejo da matéria prima desde sua retirada da mata: "Tirava mais na lua minguante, pra não apodrecer a madeira, palha, cipó" disse Dona Tereza B., da comunidade Estreitinho. Seu Paulo M., da vizinha comunidade Areia Branca, ainda comenta que "a gente que conhece sabe só no olhar qual que tá mais maduro".

Cipós eram utilizados na produção de pás, peneiras, cestas, tipiti, cercas e redes. Os balaios e as peneiras eram confeccionados com taquaruçu, os cestos com taquara-lixa e cipó-peva (também utilizado para a confecção de chapéus), e as cordas para pesca, por sua vez, com cipó-peva e cipó-embé. A oralidade presente na cultura tradicional perpetua os rituais de coleta e uso dos recursos naturais. Um exemplo disso são as várias citações para a extração dos cipós e taquaras: Dona Anadil: "tem que cortar na minguante pra não prejudicar o pé, tem que propagar pra não acabar (...) pegar a muda do cipó, cortar um pedaço e colocar no pé da árvore grande porque quanto maior a árvore ela vai dar melhor o cipó (...) tem uma época que dá a florada e ela seca, a taquara seca, então por isso que a gente tem que cuidar do que tem, é natural secar". Seu Benedito: "Ela seca de 7 em 7 anos. O índio conhece a idade pela seca das taquaras (...) o embé é mais resistente que o peva, só que tem que tirar e utilizar com a casca (...) a casca do embé é mais resistente que o coração dele (...) se tirar o cipó peva na lua crescente arrebenta a mãe".

Uma das dificuldades para o exercício dessa arte é a disponibilidade dos recursos naturais. O que era encontrado com facilidade, hoje em dia demanda mais procura e dedicação. Cabe recordar que as sociedades tradicionais, ao contrário do que está estipulado pela concepção de "paraíso perdido", engendraram sua própria versão da crise ambiental, que eclodia com base em mecanismos históricos, sociais e culturais específicos destas. (WALDMAN, 2006)

A consciência de conservação e manejo sustentável da mata é predominante entre os quilombolas e muitos já praticam o plantio de espécies nativas nas adjacências de suas moradias. Como diz Seu Osvande M. em relação ao Jatobá, espécie de difícil reprodução por ser apreciado pela fauna: "A gente tem muita preocupação, pois tá quase em extinção, a gente tem muito saco com muda pra ser plantado"

Percebe-se que os hábitos de uso e manejo dos recursos em áreas que não foram ocupadas pelo pinus e por pastagens, até hoje estão produzindo alimentos e abrigam florestas, o que afirma as comunidades do entorno do PEL. São agentes de conservação da natureza, que merecem maior visibilidade dentro do processo de elaboração de políticas públicas ambientais e culturais. (MOSCAL; KAMINSKI, 2008). 
No Paraná, os métodos de manejo dos recursos naturais desenvolvidos pelas comunidades tradicionais vem ganhando reconhecimento do poder público, que aos poucos agrega em suas pastas ações de fomento ao discurso e às práticas conservacionistas. O depoimento de Guilherme Camargo Vasconcelos, diretor do Departamento de Áreas Protegidas e Biodiversidade do Instituto Ambiental do Paraná, aponta um posicionamento favorável aos usos que as comunidades quilombolas do entorno do PEL fazem da área, "o uso dos recursos naturais pelas comunidades tradicionais vem se mostrando ao longo dos anos que não é degradante, é um uso mais sustentável, eles estando ali preservam a biodiversidade".

O PEL, quando criado em 1979, não diferenciava a população local segundo sua origem, referindo-se a todos como 'posseiros'. Como comenta Nelson Adamovicz, funcionário há 30 anos do IAP, "hoje o PEL conta com 30mil hectares de terras bem preservadas, com várias grutas, várias cachoeiras, alguns ribeirões bastante interessantes com águas límpidas e fauna abundante, sendo que houve remanejamento de posseiros em alguns locais".

A relocação das famílias que habitavam o então interior do PEL foi direcionada para a comunidade de São João. Segundo Löwen Sahr et al. (2011), além de perder parte de seu território para o estado, a maioria das famílias assentadas, com as quais os quilombolas não mantinham laços de identidade, vendeu suas posses a terceiros - sitiantes e fazendeiros - e as terras não voltaram mais aos seus "legítimos donos".

Embora o PEL não esteja na pauta do debate que envolve grandes conflitos entre áreas protegidas e populações humanas, o que se questiona é como relacionar os objetivos conservacionistas com o respeito e a manutenção da sociodiversidade em esfera local e regional.

A legislação ambiental brasileira divide as áreas protegidas em dois grupos, nomeadas enquanto unidades de conservação de proteção integral e de uso sustentável. Esta última abriga as duas únicas categorias que foram especificamente destinadas a abrigar populações tradicionais e a proteger os meios de vida e a cultura dessas populações, as RESEX e as RDS.

Após anos de debates institucionais e reivindicações por parte de comunidades tradicionais do Vale do Ribeira paulista, criou-se um modelo de reclassificação de áreas protegidas: o Mosaico de Unidades de Conservação do Jacupiranga. Entre as 16 categorias de unidades de conservação que o compõe, está a RDS dos Pinheirinhos, ocupada por três comunidades tradicionais, entre elas Areia Branca, que apesar do limite interestadual foi incluída devido à dinâmica social estabelecida com o município de Barra do Turvo (SP).

\section{CONSIDERAÇÕES FINAIS}

O sucesso das políticas de conservação da biodiversidade depende muito mais da ação coletiva nos subsistemas social e político dos atores em confronto do que das características culturais dos usuários diretos e indiretos dos recursos a serem preservados. (FERREIRA, 2004). 
Desse modo, no que tange aos elementos materiais da invisibilidade quilombola paranaense, observa-se uma dinâmica contraditória. Ao mesmo tempo em que o estado do Paraná acentua a situação de invisibilidade, não só ao criar, mas ao manter o parque com acesso proibido, reconhece estas populações, disponibiliza recursos a elas e cria programas. Contudo, as ações do próprio poder público para com as comunidades não se efetivam por conta do mesmo. (SILVA, 2013).

Atualmente a criação de Unidade de Conservação é uma das principais formas de intervenção do Estado para a redução da perda de biodiversidade diante ao avanço da degradação ambiental imposta pela sociedade. Considerar os aspectos antrópicos do interior e entorno de áreas naturais protegidas é uma ação governamental recente e de grande relevância para a conservação dos recursos naturais em ecossistemas exemplares, e que corrobora para a gestão participativa dos recursos naturais resguardada pelo SNUC.

O Vale do Ribeira, então permeado de áreas protegidas e de comunidades tradicionais é um território propenso para o desenvolvimento de atividades de cunho etnoconservacionista, cabendo à sociedade e ao governo reconhecerem e demonstrarem interesse sobre esta realidade. Agregar os saberes quilombolas e incluir o interesse das comunidades do entorno na gestão do PEL é uma ação premente para a conservação efetiva da unidade de conservação e preservação das tradições dos remanescentes culturais e naturais do território.

Com a difusão do etnoconhecimento das comunidades quilombolas do entorno do PEL pretende-se dar notoriedade à relação sociedade-natureza e incentivar novos trabalhos que resultem na permanência dessas reminiscências históricas aliadas à conservação do ambiente em que esses remanescentes culturais e naturais se fazem presentes.

\section{REFERÊNCIAS}

ARRUDA, R. Populações tradicionais e a proteção dos recursos naturais em unidades de conservação. Revista Ambiente e Sociedade, São Paulo, v. 2, n. 5, p.79-92, 1999.

BONNEMAISON, Joel. Viagem em Torno do Território. In: CORRÊA, R.L.; ROSENDHAL, Z. Geografia Cultural: um século. Rio de Janeiro: Ed. UERJ, 2002. p. 83-131.

BRASIL. Decreto n. 6040 de 07 de fevereiro de 2007. Institui a Política Nacional de Desenvolvimento Sustentável dos Povos e Comunidade Tradicionais. Diário Oficial da União, Brasília, 08 fev. 2007, p. 316.

DEPOIMENTOS. Projeto Quilombolas das Lauráceas - Difusão do Patrimônio Cultural do Vale do Ribeira Paranaense. FUNARTE, MINC. Entrevistas cedidas à Jandaíra S. Moscal e Tatiana C. G. Kaminski, 2011.

DIEGUES, A. C. (Org.). Os saberes tradicionais e biodiversidade no Brasil. São Paulo: MMA/COBIO/ NUPAUB/USP, 2000.

HAESBAERT, R. Do “Fim dos Territórios” à Multiterritorialidade. Rio de Janeiro: Bertrand Brasil, 2011.

LÖWEN SAHR, C.L.L. et al. Geograficidades Quilombolas: estudo etnográfico da Comunidade de São João, Adrianópolis - Paraná. Ponta Grossa: EDUEPG, 2011.

MOSCAL, J. S; KAMINSKI, T.C.G. As políticas públicas de conservação da natureza e os remanescentes de quilombo do Vale do Ribeira paranaense. In: IV REDES DE ESTUDOS RURAIS, 2010, Curitiba. Anais eletrônico. Curitiba: UFPR, 2010. Disponível em: <www.redesrurais.org.br>. Acesso em: 10 jun. 2014. 
PÁDUA, M.T.J. Unidades de Conservação: muito mais do que Atos de Criação e Planos de Manejo. In: MILANO, M.S. (Org.) Unidades de Conservação: atualidades e tendências. Curitiba: Fundação O Boticário de Proteção à Natureza, 2002. p. 7-13.

PRIMACK, R.B.; RODRIGUES, E. Biologia da Conservação. Londrina: Ed. do autor, 2001. 328 p.

SILVA, C.H. Quilombolas paranaenses contemporâneos: uma identidade territorial agenciada? Uma análise a partir do exemplo de Adrianópolis no Vale do Ribeira Paranaense. 2013. Tese (Doutorado em Geografia) - Universidade Federal do Paraná, Curitiba, PR.

TOLEDO, V.M.; BARRERA-BASSOLS, N. A etnoecologia: uma ciência pós-normal que estuda as sabedorias tradicionais. Revista Desenvolvimento e Meio Ambiente, n. 20, p. 31-45, jul./ dez. 2009.

VALLEJO, L.R. Unidades de Conservação: uma discussão teórica à luz dos conceitos de territórios e de políticas públicas. Revista Geographia, Rio de Janeiro, v. 4, n. 8, 2002.

VIANNA, L.P. De invisíveis a protagonistas: populações tradicionais e unidades de conservação. São Paulo: Annablume, 2008.

VIERTLER, R.B. Ecologia cultural: uma antropologia da mudança. São Paulo: Ática, 1988, 34p. (Princípios, 148)

WALDMAN, M. Cultura, mundo tradicional e meio ambiente. In: Meio Ambiente e Antropologia.

São Paulo: SENAC, 2006. p. 45-69.

Recebido para avaliação em 16-05-2014

Aceito para publicação em 08-03-2015 